\title{
Abrigar, educar e instruir: a política higienista e a educação de meninas desvalidas nas instituições de assistência no Pará (1850-1910)
}

\section{Shelter, educate and instruct: the hygienist policy and the education of helpless girls in the assistance institutions in Pará state (1850-1910)}

\author{
Laura Maria Silva Araújo Alves*
}

\begin{abstract}
RESUMO
Este artigo tem por finalidade contextualizar a trajetória de duas instituições educativas para meninas desvalidas, órfãs e em situação de abandono, na cidade de Belém do Pará, no período do Império à República. Sabe-se que com a política higienista, as meninas eram encaminhadas às autoridades que tinham a função de recolhê-las e enviá-las para instituições que as abrigassem, lhes dessem instrução, educação e formação moral, a fim de se tornarem "mães de família" ou "filhas de criação". O Colégio Nossa Senhora do Amparo (1838) e o Orphelinato Paraense (1893) foram instituições que, sob à égide da caridade e da assistência, desenvolveram uma educação feminina no atendimento à infância desvalida na capital paraense.
\end{abstract}

Palavras-chave: Meninas desvalidas. Educação. Higienismo. Infância.

\section{ABSTRACT}

This study aims to contextualize the trajectory of two educational institutions created in Belém, capital of Pará state, in the period of the Brazilian Empire to the installment of the Brazilian Republic, for helpless, orphaned and

* Universidade Federal do Pará. Instituto de Ciências da Educação. Programa de Pós-Graduação em Educação. Belém, Pará, Brasil. E-mail: laura_alves@uol.com.br. https://orcid. org/0000-0003-2936-605X. 
abandoned girls. It is known that, with the hygienist policy, girls were referred to authorities who had the task of collecting them and sending to institutions that sheltered and provided moral education training, so as to become "mothers" or "foster daughters". The Nossa Senhora do Amparo School (1838) and Orphelinato Paraense (1893) were institutions that, under the aegis of charity and assistance, developed a feminine education in vulnerable child care in the capital of Pará.

Keywords: Helpless Girls. Education. Hygienism. Childhood.

\section{Introdução}

Na segunda metade do século XIX e início do século XX, foram criadas, na capital do Pará, instituições para abrigar, educar e instruir meninas desvalidas como medida higienizadora e civilizatória sob a égide de uma pedagogia feminina. Assim, surgem o Colégio Nossa Senhora do Amparo e o Orphelinato Paraense. Tais instituições tinham como objetivo transformar as crianças pobres, desvalidas e órfãs em mulheres que tivessem uma educação doméstica; portanto, preparadas para o casamento e para se tornarem "boas mães de família". Porém, parte das meninas, oriundas do Amparo e Orphelinato, serviram à elite como "filhas de criação". Não raro, famílias abastadas da capital paraense recorriam às referidas instituições de assistência em busca de educandas dispostas a trabalhar em atividades domésticas, pois elas possuíam uma formação adequada para atender à elite paraense.

Desse modo, o presente artigo tem como objetivo uma discussão sobre o papel da política higienista no Pará e sua repercussão na criação de instituições para abrigar, educar e instruir meninas desvalidas. As questões que norteiam a construção do artigo são: (1) que políticas higienistas foram implementadas no Pará e suas relações com o recolhimento de meninas desvalidas? (2) que papel político e educativo o Colégio Nossa Senhora do Amparo e o Orphelinato Paraense tiveram na educação de meninas desvalidas em Belém do Pará?

Metodologicamente, utilizamos três produções acadêmicas desenvolvidas por pesquisadores da região Norte que investigaram as duas instituições educativas. Na primeira, sobre o Colégio Nossa Senhora do Amparo, analisamos a dissertação de mestrado de Elianne Barreto Sabino denominada A assistência e educação de meninas desvalidas no Colégio Nossa Senhora do Amparo na Província do Grão-Pará (1860-1889), defendida no Programa de Pós-Graduação em Educação da UFPA em 2012. A segunda, sobre o Orphelinato Paraense, 
aproveitamos duas produções acadêmicas: a dissertação de mestrado de Adriene Suellen Ferreira Pimenta, intitulada Educação de Meninas no Orphelinato Paraense (1893-1910), defendida no Programa de Pós-Graduação em Educação da Universidade do Estado do Pará, em 2012; e a tese de doutorado de Antonio Valdir Monteiro, denominada Órfãs e desvalidas: a formação de meninas no orphelinato municipal de Belém do Pará (1893-1931), defendida em 2013 no Programa de Pós-Graduação em Educação da Universidade de Uberlândia. Utilizamos ainda artigos e livros sobre a temática no âmbito nacional e local. Para contextualizar aspectos econômicos, políticos e sociais do Pará dos séculos XIX e XX e a política higienista, buscamos produções de autores locais como Vianna (1906), Sarges (2010) e Rocque (1996).

Para elaboração do artigo, resolvemos dividi-lo em duas partes: a primeira, sobre a política higienista e o recolhimento de meninas desvalidas (1850-1910), em que destacamos uma contextualização econômica, política e social da cidade de Belém e a política higienista e as ações de seus reformadores em Belém do Pará; e, a segunda, sobre a criação de instituições educativas a fim de abrigar, educar e instruir meninas desvalidas, abordamos os seguintes aspectos: (1) a origem e a criação das instituições e suas práticas de recolhimento das educandas e (2) o ensino e a pedagogia do trabalho.

\section{Política higienista e o recolhimento de meninas desvalidas (1850-1910)}

No início do século XIX, a população de Belém vivia em espaços alagadiços, e a geografia da cidade dificultava a urbanização em razão da quantidade de rios que tornavam os bairros pantanosos e de difícil implementação de políticas de saneamento, como, por exemplo, o abastecimento de água, a coleta de lixo e o calçamento. A população, à época, vivia de forma precária e era atingida principalmente por inúmeras doenças relacionadas à falta de higiene (MIRANDA; BELTRÃO; HENRIQUE; BESSA, 2015).

Dos anos de 1848 a 1859, a cidade de Belém passou por radicais mudanças higiênicas e sanitárias. Saltava aos olhos de quem presenciou essas mudanças. O naturalista inglês Henry Walter Bates, ao chegar à cidade de Belém em 1848, ficou assustado com as condições precárias da cidade, principalmente, com o abandono visível de seu povo. "As casas, em sua maioria, achavam-se em estado bastante precário, e por toda parte se viam sinais de indolência e desleixo" (BATES, 1979, p. 12). Ao rever a cidade em 1859, o viajante naturalista se surpreendeu com as transformações. Diz ele: “[...] achei o Pará muito modificado 
e melhorado. Não era mais aquele lugar com aspectos de aldeia cheia de mato, ameaçando ruína, que eu vira quando a conheci em 1848". Complementou o viajante ainda: "[...] as ruas outrora sem calçamento e cheias de pedras soltas e areia, estavam agora caprichosamente pavimentadas" (BATES, 1979, p. 392-396).

O Norte era conhecido como terra de índio, com população indolente, mal-educada, desleixada e, em decorrência de sua geografia, mostrava-se como um lugar insalubre. No mais, havia uma ideia ideologicamente construída nacionalmente, em que os povos da região Amazônica eram rudes e que deveriam ser moldados para um comportamento civilizado. Entre os anos de 1897 a 1911, a cidade de Belém passou a ser administrada pelo intendente Antônio José de Lemos ${ }^{1}$, o qual foi o principal responsável pela busca da modernidade e de um modelo civilizador para Belém do Pará. Seu grande desejo era fazer da capital do Pará uma pequena "Paris" nos trópicos. Para isso, Lemos empreendeu transformações significativas na infraestrutura da cidade, como tratamento de praças, parques, calçamento e arborização de ruas, abertura de estradas e criação de bulevares.

Em razão da ascensão da burguesia extrativista da borracha, esse projeto de modernização, por meio de medidas de urbanização sanitarista, contribuiu para que, de um lado, Belém se tornasse uma cidade salubre e atraente para o estrangeiro; de outro, atendia aos anseios da elite paraense que desejava viver em um lugar civilizado, moderno. Entretanto, para atingir tal modernidade, era preciso que a população tivesse mentalidade civilizada, isto é, deveria apresentar comportamentos, hábitos e costumes refinados, compatíveis com um lugar desenvolvido (SARGES, 2010). Esse ideário de civilidade se acentuou com a Proclamação da República, pois as elites brasileiras desejavam um lugar diferente. Fazia-se necessário então educar uma nação que guardava resquícios da Abolição da Escravidão, ou seja, precisava reeducar a raça (BONFIM, 2017).

É neste cenário higienista que doentes, velhos, escravos e crianças que se encontravam nas vias públicas esmolando ou em situação de abandono incomodavam o grande reformador Antônio Lemos, a ponto de ele estabelecer

1 Antônio José de Lemos nasceu em São Luís, no Maranhão, em 17 de dezembro 1843, e faleceu no Rio de Janeiro em 2 de outubro de 1913. É considerado o mais importante intendente de Belém de 1897 a 1911. Lemos foi o principal responsável pela transformação sanitária da cidade no início do século XX. Modernizou a cidade de Belém dando-lhe um ar de bela metrópole nos trópicos. Sua carreira política começou em 1885 no Partido Liberal que o elegeu deputado provincial. Quando ocorreu a Proclamação da República, Lemos exercia o cargo de presidente da Câmara Municipal, também foi jornalista, político e administrador. Fez da Província do Pará o melhor jornal que circulava na capital do Pará. Sua personalidade demonstrava um homem metódico, organizado e ambicioso. Diferenciou-se dos velhos políticos em razão da sua proximidade com o homem da terra, dos considerados eleitores "rudes e grossos". 
algumas medidas de higiene, como a limpeza na cidade com a retirada dessa população (ROCQUE, 1996). Houve então uma política de fiscalização com a atuação de agentes municipais na educação da população, tanto que se estabeleceu a criação de "instituições civilizadoras" para abrigar crianças pobres e desvalidas e o asilo de mendicidade para acolher os velhos e indigentes. Por ter administrado a cidade de Belém por 14 anos, Lemos ficou conhecido como um gestor moderno, à frente do seu tempo, pois transformou a cidade num lugar atraente aos olhos dos estrangeiros e almejado pela elite local (SARGES, 2010). No governo do intendente Antônio Lemos, houve não somente uma preocupação com a saúde da população, mas, sobretudo, em criar uma imagem positiva da cidade para os imigrantes estrangeiros e brasileiros.

No início do século XX, ainda sob a intendência de Antônio Lemos, a cidade de Belém sofrera considerável modernização. Viajantes que estiveram em Belém nos finais do século XIX e início do XX descrevem com precisão as mudanças pelas quais a cidade, metrópole da Amazônia, sofrera para se modernizar e apresentar-se ao mundo civilizado como um lugar próspero de gente elegante na sua aparência ${ }^{2}$. Euclides da Cunha, de passagem por Belém, em dezembro de 1904, numa carta escrita ao seu pai, demonstra a surpresa que a cidade lhe causou. Revelou que "nunca São Paulo e Rio terão as suas avenidas monumentais, largas de 40 metros e sombreadas de filas sucessivas de árvores enormes". Comenta ainda sua surpresa com a arquitetura e o espírito de sua gente: "[...] não se imagina no resto do Brasil o que é a cidade de Belém, com seus edifícios desmensurados e suas praças incomparáveis e com a sua gente de hábitos europeus, cavalheira e generosa" (ROCQUE, 1996, p. 26).

$\mathrm{O}$ embelezamento da cidade e o ar de progresso e modernidade fez com que, no cenário internacional, Belém ficasse conhecida como a "francesinha do Norte". A elite econômica - composta pelos barões da borracha, comerciantes, políticos e seus principais reformadores - seguiu o ideário de modernidade nacional. Para tal, utilizou um modelo de ações higienistas que tinham o propósito de abrigar, educar e instruir a população de meninas desvalidas.

2 Os viajantes estrangeiros são unânimes em suas narrativas em apontar a elegância com que as damas paraenses se apresentavam nos grandes eventos sociais. A classe abastada era influenciada pelas indumentárias europeias, tanto que as mulheres mandavam buscar seus vestidos e adereços nas melhores lojas de Paris e Londres. Para atender a essa clientela feminina, muitos estabelecimentos comerciais se instalaram em Belém, como: a Paris N'América e Maison Française, na venda de fazendas e chapéus, respectivamente. 


\section{Criação de instituições educativas para abrigar, educar e instruir meninas desvalidas}

A Casa do Recolhimento das Educandas - que posteriormente deu origem ao Colégio Nossa Senhora do Amparo - foi fundada pelo arcebispo D. Caetano Brandão ${ }^{3}$, na Província do Grão-Pará, após quatro viagens entre 02 de julho de 1785 e 08 de março de 1789 pelo interior do Pará e Amazonas. O arcebispo, enfrentando fadiga, pragas, doenças, epidemias e, principalmente, intempéries da região Amazônica, trouxe 15 meninas índias em situação de abandono e pobreza pela região para serem cuidadas na capital da província. Essa instituição foi construída como resultado de seu empenho e dedicação com as indígenas, mas só inaugurado no dia 10 de junho de 1804 pelo bispo D. Manuel de Almeida Carvalho, que deu continuidade à Obra Pia do Frei Caetano Brandão.

D. Manoel de Almeida Carvalho era o $7^{\circ}$ pastor da diocese do Pará em 1794. No ano de 1804, ao retornar de visita do interior do estado, trouxe também algumas índias as quais prometera educação. Movido pelo mesmo desejo de D. Frei Caetano Brandão, D. Manoel de Almeida Carvalho fundou um asilo para educar estas meninas desamparadas. Embora tivesse boa vontade de manter a educação de meninas desvalidas, o funcionamento da instituição dependia da ajuda de pessoas que viam nesta obra de caridade uma possibilidade de ajudar aos mais necessitados. Contudo, a manutenção da instituição tornou-se difícil, visto que os custos eram elevados comparados aos auxílios recebidos que eram ínfimos (VIANNA, 1906).

Ao longo das primeiras décadas do século XIX, a referida instituição, já conhecida como Colégio Nossa Senhora do Amparo, passou a abrigar e dar uma educação digna às meninas desprovidas de recursos e abandonadas na região da Província do Grão-Pará, em um contexto de uma sociedade que vivia na busca do progresso social e moral do povo. Os reformadores, à época, defendiam uma política de limpeza nos espaços públicos e a retirada de crianças pobres e abandonadas das ruas. Abrigá-las, instruí-las e educá-las eram as medidas de civilidade na Província do Grão-Pará, uma vez que, ao permanecerem em condições de abandono, demonstraria aos olhos da elite uma falta de piedade com os mais necessitados e geraria, sobretudo, um aspecto de não civilidade. Ainda

3 Frei Caetano Brandão deixa a Província do Grão-Pará em 1789; e, no dia 28 de junho de 1790, assumiu a Arquidiocese de Braga em Portugal. Morreu aos 65 anos, em Portugal, no dia 15 de dezembro de 1805. Disponível em: < http://www.monumentosdebelem.ufpa.br/transcodificacao/ index.php/monumento/frei>. Acesso em: 10 dez. 2017. 
sob a égide da caridade e de um modelo europeu, o Colégio do Amparo recolhia as meninas, dava-lhes uma formação cristã, o aprendizado das primeiras letras e os conhecimentos necessários para uma formação feminina.

Embora Sabino (2012) não tenha destacado qualquer menção de que o Colégio do Amparo tivesse alguma semelhança com o modelo de recolhimento de meninas, meninos, velhos, doentes, prostitutas em Portugal; Abreu (2014, p. 181) diz que, no contexto lusitano, entre os séculos XVII e XVIII, "filósofos e reformadores sociais, políticos e homens da Igreja, de inspiração humanista", como Dom Frei Caetano Brandão, apoiaram os mais desfavorecidos com a criação de instituições, "transferindo para elas responsabilidades que pertenciam à esfera familiar e privada". Enfim, segundo a autora, as intenções reformistas e catequéticas, como o Concílio de Trento $^{4}$, foram fundamentais na organização e disseminação das políticas de institucionalização de entidades de assistência. O movimento fundacional das instituições de recolhimento de meninas pobres, desvalidas e órfãs em Portugal demonstra que o modelo das "Casas Pias" foi eminentemente urbano, com incidência nas sedes dos arcebispados de Lisboa, Braga e Évora, tais como: o Recolhimento Nossa Senhora do Carmo e Casa Pia, em Lisboa; Colégio São Caetano, em Braga; e Colégio dos Santos Inocentes, em Évora.

Ao chegar no Pará em 1782, o Frei Brandão realizou significativas obras em terras paraenses, no que lhe foi atribuído a denominação de "apóstolo dos enfermos" por sua preocupação com enfermos, pobres, desvalidos e indígenas. No livro Diário das Visitas Pastorais no Pará, de D. Frei Caetano Brandão, escrito pelo Dr. Oliveira Ramos, diz que o religioso, ao retornar à Braga, em 1790, dedicando-se à caridade, trouxe para junto de si os deserdados e as crianças carecidas de educação no Norte de Portugal. As políticas assistenciais implantadas em Portugal correspondiam ao novo ideário social, que assumia, de um lado, a pobreza como uma situação transitória; de outro, o poder político como responsável pela capacitação dos infelizes necessitados por meio da educação e trabalho, pois eram instrumentos que certamente garantiriam suas melhoras de vida. (ABREU, 2014).

De acordo com o levantamento de Abreu (2014) sobre instituições de acolhimento de crianças em Portugal, o Colégio do São Caetano, em Braga, teria sido fundado a partir do modelo da Casa de Recolhimento das Educandas na

4 O Concílio de Trento foi o $19^{\circ}$ conselho ecumênico reconhecido pela Igreja Católica Romana. Foi realizado em 1542 e desenvolvido pelo Papa Paulo III. Teve a duração no período entre 1545 e 1563 . Foi denominado por este nome em razão de ter sido realizado na cidade de Trento, região Norte da Itália. Concílio de Trento foi uma reação da Igreja Católica à Reforma Protestante, iniciada por Martinho Lutero na primeira metade do século XVI. 
Província do Pará, já que foi fundada pelo arcebispo D. Frei Caetano Brandão em 1790, após seu retorno a Portugal.

Ao que tudo indica, o Colégio do Amparo funcionou em casas alugadas e com uma infraestrutura precária nos primeiros anos de sua existência. Em outubro de 1865, o Dr. José Vieira Couto de Magalhães efetivou compra de um grande prédio para instalar o Colégio, mas precisava de reformas para que fosse ocupado adequadamente pelas educandas e pela sua diretoria. Essa reforma foi realizada entre 1868 e 1869. Além disso, a comissão de senhoras que gerenciava a manutenção das educandas foi abolida.

No Brasil, até o final do século XIX, o ideário de caridade e filantropismo serviu de modelo para o surgimento de variadas instituições a fim de receber meninas desvalidas. Em 13 de maio de 1893, na capital do Pará, fundou-se a Orphelinato Paraense a partir da criação da Associação Protectora dos Órfãos.

Imbuído do "sentimento humanitário de algumas famílias da elite paraense", inaugurou-se em 1893, com o apoio do governador do Estado, uma entidade filantrópica chamada Associação Protectora dos Órphãos. A entidade protetora era composta por membros associados que, por meio de doações e trabalhos voluntários, atuavam em prol dos órfãos e dos desvalidos de Belém (MONTEIRO, 2013, p. 30-31). Por volta de 1906, o Orphelinato Paraense passou a se chamar Orfanato Antônio Lemos. Contudo, no ano de 1900, em razão dos poucos recursos para a manutenção da instituição, a diretoria do orfanato pediu ajuda a Intendência Municipal de Belém, que tinha como principal representante na época o intendente Antônio José Lemos.

A iniciativa de criação da Associação Protectora das Órfãs e do Orphelinato foi do governador do Estado, Sr. Lauro Sodré. Segundo Pimenta, para a inauguração do Orphelinato Paraense, foi necessária uma mobilização para obter fundos financeiros que seriam depositados na conta da Associação Protectora dos Órphãos. A finalidade era construir uma instituição que daria às órfãs "casa, mesa, luz, vestuário, instrução primária, ensinando-se aos do sexo feminino toda sorte de costura, chá, prendas de agulha, e serviços domésticos." (PIMENTA, 2012, p. 37).

Em 19 de julho de 1898, foi assinado um contrato entre a Associação Protectora dos Órfãos e a Ordem das Filhas de Sant'Anna ${ }^{6}$. Assim, aproximadamente

5 Dom Frei Caetano Brandão era religioso da Ordem Terceira da Penitência do Seráfico Padre São Francisco. Ele nasceu em Portugal, no dia 11 de setembro de 1740 e faleceu aos 65 anos em Portugal, no dia 15 de dezembro de 1805. Tornou-se padre aos 19 anos em 1759, sendo nomeado bispo do Pará no dia 16 de dezembro de 1782.

6 A congregação Instituto das Filhas de Sant'anna foi fundada pela italiana Rosa Maria Benta Gattorno (1831-1900). Nascida em 14 de outubro de 1831, em Gênova, na Itália; casou-se aos 21 anos com Jerônimo Custo, mas sofreu precocemente a dor da perda do esposo após seis 
oito religiosas da congregação assumiram a administração da instituição. Elas chegaram a Belém, por volta de 1884, a convite do respeitado bispo da cidade, D. Macêdo Costa, para administrar o Hospital Bom Jesus dos Pobres, depois denominado Santa Casa de Misericórdia do Pará. A unidade de saúde, cujo provedor era o Dr. Ferreira de Freitas, estava com dificuldades administrativas, carecia de melhor infraestrutura e uma atenção mais humanizada para os doentes. Daí a importância das religiosas no cuidado e administração do hospital. É relevante destacar o papel importante dessas religiosas na administração de instituições pelo Brasil, em especial no Pará, pois contribuíram para a formação de muitas mulheres numa época em que elas exerciam papéis secundários na sociedade.

Quando assumiram a direção do Orphelinato, as referidas religiosas enfrentavam vários problemas, porque, mesmo com a administração cuidadosa das religiosas Filhas de Sant'Ana, a situação do Orphelinato era extremamente grave. A crise financeira se agravou e atingiu significativamente a instituição, de modo a comprometer seriamente o seu funcionamento. No início do ano de 1900, como era de se esperar, a situação do Orphelinato ficou insustentável, e a Associação Protectora dos Órfãos teve que intervir para manter a instituição de pé. Diante do quadro desolador que se encontrava a instituição, a diretoria da Associação Protectora dos Órphãos resolveu então buscar ajuda do Conselho Municipal de Belém, única alternativa para salvar o Orphelinato. Há indícios de que as dificuldades se avolumaram em razão do reduzido número de sócios e de doações que cobriam substancialmente as despesas da instituição. Segundo Monteiro (2013, p. 33), em poucos meses de criação da Associação Protectora dos Orphãos, o número de sócios atingiu a marca de 535, sendo que destes, 405 eram cavalheiros e os demais composto por damas da sociedade.

É importante destacar que a intenção de tomar uma instituição como o Orphelinato a cargo do Conselho Municipal seria certamente uma atitude que se aproximava da personalidade do visionário intendente, visto que Lemos, na qualidade de Senador Federal, manteve contato direto com instituições caritativas e filantrópicas, como, por exemplo, a Santa Casa de Misericórdia e instituições religiosas (MONTEIRO, 2013, p. 35-36).

O Conselho Municipal decide a partir da Lei ${ }^{\circ} 283$, de 27 de dezembro de 1900, ajudar financeiramente o Orphelinato Paraense. Coube então ao intendente Antônio Lemos ${ }^{7}$ apoio e recursos para manutenção do Orphelinato. Devido às

anos de matrimônio e, pouco tempo depois, a morte de um dos três filhos. Em 1861, após ficar viúva, a religosa entra na terceira ordem franciscana; imbuída do sentimento de caridade, dedica-se inteiramente a várias obras de apostolado social na cidade de Génova.

7 Antônio Lemos nasceu em 17 de dezembro de 1843 no estado do Maranhão e mudou-se para a cidade de Belém, no Pará, ainda muito jovem. Foi o principal responsável pelo desenvolvimento urbano da cidade de Belém, tendo projetado uma série de modificações nos finais do século 
condições do prédio serem precárias, Antônio Lemos imediatamente alugou outro prédio na Avenida São Jerônimo - hoje Avenida Governador José Malcher, entre Generalíssimo Deodoro e 14 de Março -, tentando oferecer melhores condições de abrigamento às órfãs do Orphelinato Paraense (ROCQUE, 1996, p. 441). Tudo indica que a instituição funcionou em "dois prédios ocupados pelo Orfanato à Avenida São Jerônimo", inclusive foram feitas adaptações em um dos prédios que possuía dormitório, cozinha, refeitório, salas de aula, sala de prendas, jardim, enfermaria e gabinete dentário. A idade mínima de uma órfã para adentrar o Orphelinato era de 4 anos (PIMENTA, 2012, p. 78).

Diante de um contexto econômico, político e social favorável, o intendente Antônio Lemos decidiu construir um prédio para o orfanato no caminho da estrada de Bragança. Tal afastamento da cidade se justificava, de um lado, devido à qualidade da educação dada às órfãs e, de outro, por a estrada de Bragança representar um progresso para a capital, uma vez que era por essa estrada que escoavam mercadorias e circulavam pessoas que iam de Belém até Bragança. Imbuído desse propósito, o intendente Antônio Lemos articula politicamente, junto ao Conselho Municipal, um terreno para a construção do orfanato. "Em 1903, conseguiu dar início à construção do prédio próprio na Vila de Santa Isabel" (PIMENTA, 2012, p. 80).

Há informações de que a relação de Lemos com o Orphelinato Paraense já se estabelecia desde a sua atuação como redator chefe do Jornal A Província do Pará onde publicou variadas matérias sobre a instituição. É óbvio que ao se tornar intendente de Belém e ter adquirido o prestígio de toda a direção da instituição, o intendente se dedicou muito mais ao Orfanato Antônio Lemos, a ponto de "doente receber a visita das órfãs em sua residência". Tal gesto das educandas simbolizava uma forma de respeito e reconhecimento pelos serviços prestados à importante instituição educativa (PIMENTA, 2012, p. 71).

Em 1903, com a ajuda de Antônio Lemos, iniciou-se a construção de um prédio na Vila de Santa Izabel para transferir o Orphelinato. Em 1906, o iminente intendente baixou um decreto sob o qual o Orphelinato passou a ser chamado de Orfanato Antônio Lemos. Indiscutivelmente, ao longo dos anos de existência do Orphelinato Paraense, Lemos teve um papel fundamental na sua manutenção e nas várias transformações pelas quais passou a instituição. Sua relação com o orfanato era tão visceral que, em 17 de dezembro de 1908, na celebração de seu aniversário, Lemos não quis missa na Catedral como era de costume, mas no orfanato "onde chegou às 7 horas da manhã, sendo recebido pelas freiras,

XIX e início dos XX. Foi jornalista, político e administrador. A carreira política de Antônio Lemos se iniciou em 1885 quando o Partido Liberal, do qual era membro, o elegeu deputado provincial pelo $1^{\circ}$ e $5^{\circ}$ Distrito. 
pelas internas e pelo alto mundo político e social que saíra de Belém mais cedo para esperá-lo à porta e saudá-lo" (ROCQUE, 1996, p. 45). Mas, que motivação Lemos tivera para manter tal instituição de pé?

Como dedicado gestor, tudo leva a crer que o intendente, movido pela modernização da cidade e de uma política higienista e sanitarista, acreditava que a criação desta instituição favorecia não somente o embelezamento e a limpeza da cidade, mas também que as meninas pobres, desvalidas e órfãs estariam livres dos males do abandono e principalmente do perigo das ruas. Era recorrente na capital do Pará meninas em situação de abandono e orfandade serem defloradas em razão das condições de vulnerabilidade que elas se encontravam (SERFATY, 2016). Outro fator que consideramos relevante refere-se à direção do Conselho Municipal e da obra inovadora que motivara Lemos, posto que o orfanato passou a ter credibilidade e prestígio não somente perante à população abastada, mas também desfavorecida que via na instituição uma maneira de amparar meninas desafortunadas por uma política de formação feminina. Isso se evidenciou claramente no ano de 1900. A instituição que abrigava apenas 9 órfãs, logo teve um aumento extraordinário de meninas abrigadas no ano de 1903, que passou a ter 80 órfãs. Em razão da procura pelo orfanato, Antônio Lemos propôs transformá-lo em Instituto Técnico Profissionalizante para trabalhos agrícolas. Tal formação promovia às órfãs, além de uma formação feminina para serem "boas mães e esposas amorosas", o aprendizado de um "ofício". Portanto, a intenção de construir o orfanato afastado do espaço urbano, ou seja, na vila de Santa Isabel, parecia se adequar ao propósito de Lemos (PIMENTA, 2012, p. 80).

Segundo Roque (1996), em ofício de $1^{\circ}$ de dezembro de 1902, Lemos oficializou a doação de um terreno pelo Tenente Coronel Antônio de Pontes Tavares para a construção do orfanato. A construção se prolongou por anos em razão da grandiosidade do prédio. Entretanto, a proposta de fazer do orfanato uma instituição técnica profissionalizante não foi concretizada. $\mathrm{O}$ "envolvimento de Antônio Lemos com a caridade e com assistência aos mais pobres" se apresentava determinante para a sua "ascensão e legitimação no cenário político paraense, lhe credenciando a colocar em prática, enquanto intendente, o seu projeto de modernização da capital", realizando significativas mudanças, principalmente no campo da assistência e da instrução na primeira década do século XX (MONTEIRO, 2013, p. 119-120).

Embasados nas "Obras Pias" de Portugal, o Colégio Nossa Senhora do Amparo e o Orphelinato Paraense passaram a receber ajuda por meio de doações de seus beneméritos e da elite local. O modelo da Casa Pia era uma política assistencial implantada com um ideário social que assumia a pobreza como uma situação transitória e o poder público como responsável pela capacitação dos pobres. Pela educação e trabalho era possível promover a melhoria de vida de 
uma população empobrecida que precisava de uma formação adequada e útil à sociedade. Portanto, acolher e (re)educar eram os pilares da proposta, pois sua missão era garantir que os pobres não morressem ao desamparo (ABREU, 2014). Os asilos, orfanatos e colégios geralmente acolhiam crianças que eram resgatadas de ruas, becos e vielas ou eram crianças de famílias muito pobres que, de certa maneira, não tinham hábitos higiênicos, causando um problema para o projeto de civilização urbana pelo qual as províncias passavam. Enfim, uma das formas de "salvar" a criança pobre, negra ou indígena - aquelas que, sob a ótica dos reformadores sociais do século XIX, deveriam ser controladas e vigiadas - era por meio da educação direcionada para o trabalho manual (pedagogia do trabalho).

Com relação às atividades aplicadas no Colégio do Amparo, as meninas recebiam uma formação cristã sob a proteção da Igreja Católica. O ensino e a educação das meninas do Amparo consistiam no Curso Primário. Fazia parte do currículo o ensino de práticas de serviços e prendas domésticas e o ensino da religião católica, destinados à formação moral/cristã das meninas. As meninas do Amparo tinham aulas de cozinha, corte, costura, confecção de flores e canto. Além de todas essas atividades que regulavam o tempo e os espaços das meninas, também havia uma educação direcionada para o aprendizado de trabalhos manuais. Tais atividades eram indispensáveis à formação da mulher, pois, à época, a mentalidade da sociedade arquitetava-se sob a égide de uma mulher preparada para ser "dona de casa" e "boas mães de família" (SABINO, 2012). Segundo Santana (2016, p. 74), "a mulher era a peça principal para a formação da nova geração de cidadãos brasileiros, ideia acalantada desde o Brasil Império. Por esse motivo, as concepções higienistas a cercavam".

Para a elite paraense, as educandas do Colégio do Amparo além de serem educadas para o casamento também eram preparadas para atender à elite local. De acordo com Sabino (2012), o plano diário de estudo das educandas consistia de leitura, gramática portuguesa, história sagrada, catecismo e aritmética. Igualmente, aprendiam diversas prendas domésticas: costurar, marcar, bordar a branco, matiz, ouro e flores, também lavar, engomar e cozinhar. As educandas aprendiam, ainda, a cantar (canto coral etc.), declamar, orar, colaborar e participar dos atos religiosos. Essa educação foi muito questionada pelas autoridades, com o argumento de ser muito luxuosa para meninas pobres. A formação esmerada que meninas pobres e desvalidas recebiam no Colégio do Amparo se justificava em razão de prepará-las para servir à elite local, pois, como já mencionamos anteriormente, era comum que famílias tradicionais da sociedade paraense recorressem à instituição para obter as chamadas "filhas de criação"s.

8 "Filhas de criação" eram um termo muito utilizado pela elite paraense no século XIX para chamar a menina que saía do Colégio do Amparo para trabalhar como serviçal nas casas de 
Ao longo da sua existência, o Colégio do Amparo desenvolveu, no mesmo espaço físico, duas obras educacionais: havia, de um lado, uma educação destinada às crianças órfãs e desvalidas e, de outro, a educação de filhas da elite paraense, as chamadas meninas pensionistas. Enquanto as pensionistas usufruíam de uma educação refinada que lhes possibilitasse a condição de damas do salão, compatível com suas condições econômicas favoráveis, as órfãs pobres, por sua vez, deviam ser preparadas para o mundo do trabalho doméstico.

Não muito diferente do ensino do Colégio do Amparo, o Orphelinato Paraense também desenvolveu um ensino voltado para preparar meninas sob a proteção de uma educação para serem "mães de família". As educandas do Orphelinato Paraense recebiam o ensino primário com o objetivo de apreender as primeiras letras. Havia a distribuição das meninas em classes, ou seja, por grau de aprendizagem. As educandas passavam anualmente por avaliações para medir seus conhecimentos e determinar a classe que caberia as suas condições cognitivas. Conforme Pimenta (2012), a avaliação, que era feita anualmente, analisava os conteúdos em relação à parte literária, à científica e às prendas domésticas. Com relação às prendas domésticas, eram avaliados os trabalhos desenvolvidos pelas órfãs, como bordado a branco e a lã, flores de lã, costura de roupas brancas, vários tecidos em tear, crochê e labirintos. Tudo indica que essa avaliação anual era marcada como um momento importante, pois havia uma comissão de professores que estabeleciam critérios rigorosos de avaliação do desempenho das educandas. Além dessas atividades, havia ainda aulas de canto orfeônico.

Assim como as educandas do Colégio do Amparo, as do Orphelinato faziam bazares festivos com as peças manuais produzidas nas aulas de prendas para serem compradas pela elite local. As peças de costura e bordados eram comercializadas e muito apreciadas pelo público feminino de ambas as instituições como sendo de melhor qualidade, pois as educandas tinham a fama de exímias mulheres prendadas e educadas. A sociedade local apreciava os trabalhos das meninas do Orphelinato, porque era comum elas serem contratadas a fim de produzirem bordados e enxovais para noivas e batizados (PIMENTA, 2012, p. 113-114).

De acordo com dados levantados no jornal A Província do Pará, Pimenta (2012) diz que - em razão da formação disciplinada, cuidadosa em trabalhos manuais que recebia na instituição - algumas educandas foram trabalhar como costureiras em uma fábrica de luvas. É importante destacar que a proximidade

família. Em geral, a menina era prometida a cuidados e estudos, porém, não conseguiam estudar em razão de entrarem no mundo do trabalho ainda muito criança. No século XX, no contexto de Belém, as famílias abastadas procuravam meninas e meninos pobres, órfãos e do interior do estado para trabalhar em atividades domésticas e como babás. Era recorrente as meninas sofrerem maus tratos e abusos sexuais. 
do Orphelinato com o Colégio do Amparo se deu não somente pela filosofia de formação dada às meninas órfãs, mas, principalmente, pela ideologia da pedagogia para o trabalho feminino. Além disso, havia uma rede de relações que, de certa maneira, interligava as duas instituições com o mesmo propósito: preparar as educandas para serem "mulheres prendadas". Essa prática de formação para a população feminina vem da dedicação da Sra. D. Amélia Rosalina Corrêa de Farias que foi professora de prendas domésticas tanto no Orphelinato como no Colégio do Amparo (PIMENTA, 2012, p. 116).

O cotidiano das educandas do Orphelinato era bastante rígido. Havia aulas de ginástica com o objetivo de disciplinar os corpos e mentes, como também formar um corpo forte e sadio. Tinham ainda aulas de desenho e de canto orfeônico com o intuito de prepará-las para se apresentarem em pequenos espetáculos, sobretudo, quando a instituição recebia uma personalidade ilustre. Geralmente, as educandas se apresentavam com requinte e com muita habilidade para a música. Enfim, elas recebiam aulas de Arte, tais como: teatro, canto coral e piano; e ainda aulas de línguas (francês e italiano). Obviamente, que durante o dia, era estipulado um momento para orações.

A higiene das instituições que abrigavam meninas no século XIX era medida indispensável para seu funcionamento. Elas deveriam seguir o manual de higiene e fiscalização constante dos médicos nos cuidados com as educandas. No século XIX, o higienismo foi um "tema geral através do qual os médicos interessaram-se em diagnosticar e apresentar prescrições sobre a educação nos colégios". Temas como "higiene escolar", "desenvolvimento físico e moral", "desenvolvimento intelectual", "sexualidade", entre outros aparecem nas teses de medicina, pois os médicos acreditavam que seus conhecimentos científicos poderiam ordenar o espaço da escola e evitar, principalmente, a proliferação de doenças (CONCEIÇÃO, 2017). No discurso médico-higiênico, era dominante a preocupação não somente com os espaços limpos e higienizados, mas sobretudo com o desenvolvimento de vícios, de uma pedagogia do medo, dos castigos físicos e humilhantes, além de criticarem os prédios dos colégios em razão da sua ocupação excessiva e das instalações precárias.

No Colégio do Amparo, havia constantemente uma inspeção médica para que fosse evitado a proliferação de doenças, sobretudo, diante de doenças epidêmicas como varíola, tuberculose e febre amarela. Ocorreu então uma política de asseio e limpeza dos espaços da instituição para que não proliferassem doenças e causasse o falecimento de educandas. Entretanto, os médicos sanitaristas que faziam inspeção escolar estabeleceram sérias críticas às condições de higiene dos ambientes do colégio. José Veríssimo, no ano de 1890, então diretor geral da Instrução Pública do Pará, relatou as condições precárias de higiene do Colégio do Amparo durante uma visita realizada na instituição. 


\section{Considerações finais}

Este artigo procurou analisar a política higienista e algumas práticas educativas aplicadas a centenas de meninas que viveram no Colégio Nossa Senhora do Amparo e no Orphelinato Paraense, posteriormente denominado Orfanato Antônio Lemos, em um período marcado por grandes transformações políticas, econômicas e sociais na capital paraense. Inicialmente, traçamos a trajetória de duas instituições de educandas desde sua origem, trazendo à tona algumas questões, como saneamento, higiene e assistência em paralelo ao projeto de reordenamento urbano da capital paraense.

Ficou evidenciado que as disciplinas que envolviam habilidades práticas como trabalhos manuais e trabalhos de agulha e mesmo as prendas domésticas tinham prioridade em educar as meninas do Amparo e do Orphelinato para atividades domésticas. Sob constante vigilância e disciplina, as educandas de ambas instituições eram dirigidas internamente pelas missionárias da ordem religiosa italiana Filhas de Sant'Anna que implementavam uma formação educativa rígida e conservadora. Em ambas instituições, as meninas ali acolhidas eram amparadas da miséria e ignorância e se tornavam mulheres úteis à sociedade paraense. Percebemos claramente que havia uma intenção ideologicamente arquitetada para transformar a menina pobre, desvalida e órfã em uma mulher adequada para os princípios sociais e educacionais, principalmente, em termos morais, em mulheres "mães de família" e "senhoras do lar". Foi possível observar que os reformadores e a elite paraense, entre o século XIX e o XX, buscavam, por meio dos mais variados tipos de instituições, asilar meninas desvalidas em razão não apenas da política higienista, mas também de formar a população feminina com uma educação que atendesse aos interesses da sociedade paraense. $\mathrm{O}$ abrigamento dessa camada da população era justificado por um discurso que objetivava preservar a moral e os "bons costumes" da sociedade, sobretudo, daqueles que eram considerados rudes, ignorantes e sem educação moral. Nesse contexto, a sociedade paraense acreditava em uma educação atrelada ao isolamento de mulheres como a única forma de garantir "civilidade" e "modernidade"; sair, portanto, da "barbárie", aspecto incompatível com o ideário de desenvolvimento, principalmente, do regime republicano. Assim, educandas que saíam do Amparo e do Orphelinato (posteriormente Orfanato Antônio Lemos) seriam mulheres, com formação educativa, adequadamente preparadas para cuidar do lar e dos filhos. 


\section{REFERÊNCIAS}

ABREU, L. O poder e os pobres: as dinâmicas políticas e sociais da pobreza e da assistência em Portugal (séculos XVI-XVIII). Portugal: Gravita, 2014.

BATES, H. W. Um naturalista no Rio Amazonas. São Paulo: EDUSP/Itatiaia, 1979.

BONFIM, P. R. Educar, higienizar e regenerar: uma história da Eugenia no Brasil. Jundiaí: Paco Editorial, 2017.

CONCEIÇÃO, J. T. da. Internar para Educar: colégios-internatos no Brasil (1840-1950). Aracaju: Edise, 2017.

MIRANDA, C. S.; BELTRÃO, J. F.; HENRIQUE, M. C.; BESSA, B. T. Santa Casa de Misericórdia e as políticas higienistas em Belém do Pará no final do século XIX. Revista História, Ciências e Saúde, Manguinhos, Rio de Janeiro, v. 22, n. 2, p. 525-539, abr.-jun. 2015.

MONTEIRO, A. V. M. Órfãs e desvalidas: a formação de meninas no orphanato municipal de Belém do Pará (1893-1931). 2013. Tese (Doutorado em Ciências Humanas) - Programa de Pós-Graduação em Educação, Universidade Federal de Uberlândia, Uberlândia, 2013.

PIMENTA, A. S. F. Educação de Meninas no Orphelinato Paraense (1893-1910). 2012. Dissertação (Mestrado em Educação) - Programa de Pós-Graduação em Educação, Universidade do Estado do Pará, Pará, 2012.

ROCQUE, C. Antônio Lemos e sua época: história política do Pará. 2. ed. Belém: Cejup, 1996.

SABINO, E. B. A assistência e educação de meninas desvalidas no Colégio Nossa Senhora do Amparo na Província do Grão-Pará (1860-1889). 2012. Dissertação (Mestrado em Educação) - Programa de Pós-Graduação em Educação, Universidade Federal do Pará, Pará, 2012.

SANTANA, J. S. Casa de Meninas: práticas educativas no orfanato de São Cristovão e na Escola da Imaculada Conceição (1922-1969). Aracaju: Edise, 2016.

SARGES, M. de N. Belém: riquezas produzindo a Belle Époque (1870-1912). 3. ed. Belém: Pakatatu, 2010.

SERFATY, P. G. Mulher, decência e educação: análise discursiva do processo judicial de defloramento de Joanna Bentes da Silva, em Belém - Pará (1905). 2016. Dissertação (Mestrado em Educação) - Programa de Pós-Graduação em Educação, Universidade do Estado do Pará, Pará, 2016.

VIANNA, A. O Instituto Gentil Bittencourt. Belém: Imprensa Oficial do Estado do Pará, 1906. 